\title{
James L. Novak, James W. Pease, Larry D. Sanders, 2015, Agricultural Policy in the United States. Evolution and Economics, New York, U.S.A., Routledge Textbooks in Environmental and Agricultural Economics, 248 p
}

\author{
Jean-Christophe Bureau ${ }^{1}$
}

Published online: 29 March 2016

(C) INRA and Springer-Verlag France 2016

Agricultural Policy in the US: Evolution and Economics is a useful textbook for students and, more generally, for those interested in U.S. farm policy. It provides an introduction to the economic and political motivations of U.S. farm policy. It contains a description of the past and current policy instruments; an introduction to the analysis of public intervention based on welfare analysis; and an evaluation of the pros and cons of the (numerous) policy instruments used by governments in the agricultural sector.

The book contains 12 chapters, organized in what can be seen as three groups. In the first chapters, the authors provide a description of rationale for farm policies, basic economic concepts, and some (very basic) elements of political economy. Then, several chapters are devoted to the history of U.S. agricultural policy and the transition to modern farm bills. The last group of chapters deals with international trade and a (useful) description of the 2014 U.S. agricultural legislation.

It is a rather elementary textbook on economic aspects and clearly targets non-specialists, but it is clearly written and informative for those who are not familiar with the topic. The historical sections are particularly detailed. This is the case of policies implemented in past farm bills and their economic rationale at the time. This makes it possible to track the evolution and economic effects of successive legislations. It helps grasp how the current situation is the product (and

Jean-Christophe Bureau

jc.bureau@agroparistech.fr

1 AgroParisTech, Paris, France the piling up) of many past decisions. Indeed, some current instruments date back to the 1930 s and some can be tracked to nineteenth century decisions. The choice of the authors to devote a large section of the book to the policy developments that have led to the current legislation nevertheless has a cost, namely, the chapters dealing with economic analysis remain quite elementary. In some cases, it is even at the cost of excessive simplification (just to take an example: the use of Kaldor's compensation criterion in welfare analysis is taken for granted, in spite of the questionable relevance of such criterion and the many objections related to the implicit assumptions in the social choice literature). The section on "how policy is made" relies on rather unknown authors who have written about interest groups, "power clusters," and "iron triangle" models, but ignores basically all major schools of political economy, including those who have dealt with agricultural lobbies and "protection for sale." The section on international trade is very short and does not include any serious analysis of the trade agreements and their impact on U.S. policy. The biofuel policy, which plays a significant role in the determination of market prices, is not really dealt with either.

In spite of these weaknesses, the book provides a lot of information that will help the readers to understand the issues related to the agricultural policy in the USA. The final chapter on the current legislation is particularly interesting since it makes explicit the linkage between the different titles of the legislation and the economic objectives that these titles are supposed to achieve, in addition to providing a clear explanation of what is actually included in the recent legislation. Overall, the book provides a useful introduction to the topic of U.S. agricultural policy. 